ISSN: $1130-3743$

DOI: http://dx.doi.org/10.14201/teoredu2014261141162

\title{
DONACIÓN DE SANGRE Y EDUCACIÓN PARA LA CIUDADANÍA. UNA APROXIMACIÓN DESDE EL APRENDIZAJE SERVICIO Y LA TEORÍA DEL DON
}

\author{
Blood Donation and Citizenship Education. An approach \\ from service learning and the Theory of Don
}

\section{Don de sang et éducation à la citoyenneté. Une approche de l'apprentissage service et la Théorie du Don}

Josep M. Puig Rovira*, Mariona Graell Martín* y Gal·la Cortel MaÑÉ**

* Universidad de Barcelona. Facultad de Pedagogía. Departamento de Teoría e Historia de la Educación. Campus Vall d'Hebron. Passeig de la Vall d'Hebron, 171.08035 Barcelona. joseppuig@ub.edu

** Responsable de Promoción, Banco de Sangre y Tejidos de Cataluña

Fecha de recepción: marzo de 2014

Fecha de aceptación: junio de 2014

Biblid [(1130-3743) 26, 2-2014, 141-162]

RESUMEN

La donación altruista de sangre que recomienda la Organización Mundial de la Salud y que llevan a cabo los bancos de sangre, además de contribuir a proporcionar al sistema sanitario un elemento terapéutico imprescindible, es un dispositivo que regenera la convivencia social y que educa para la ciudadanía. En este marco, el artículo comienza argumentando por qué es mejor la donación altruista que la compraventa y por qué la teoría del don -que ha desarrollado la sociología a partir de la obra de Marcel Mauss- justifica bien la posibilidad de satisfacer por esta vía la demanda de sangre. A partir de estas consideraciones, se afirma que los bancos de sangre son instituciones sociales que desarrollan tres funciones básicas: técnica, 
cívica y educativa. El artículo prosigue desarrollando la propuesta educativa del Banc de Sang i Teixits (Banco de Sangre y Tejidos) de Catalunya. Un programa basado en la metodología del aprendizaje servicio que invita a los jóvenes a formarse y a desarrollar una propuesta comunicativa para promocionar la donación altruista de sangre en su entorno. El artículo concluye evaluando la consolidación, efectividad y satisfacción del proyecto, y sugiriendo que este modelo puede utilizarse para idear las propuestas educativas de otras instituciones sociales.

Palabras clave: altruismo; teoría del don; aprendizaje servicio; donación de sangre; utilitarismo; interés; banco de sangre; educación para la ciudadanía.

\section{SUMMARY}

The altruistic donation of blood recommended by the World Health Organisation and carried out through blood banks not only contributes to providing the health system with an indispensable therapeutic element, it is also a means of fostering social integration and educating for citizenship. Within this general context, the article begins by arguing why altruistic donation is better than buying and selling blood and why the gift theory - developed by sociology on the basis of the work by Marcel Mauss - more than justifies the possibility of meeting the demand for blood in this way. On the basis of these considerations it can be said that blood banks are social institutions that perform three basic functions: technical, civic and educational. The article continues by examining the educational project undertaken by the Blood and Tissue Bank of Catalonia, which consists in a programme based on the methodology of service learning and which invites young people to cultivate and develop a communicative approach to promoting the altruistic donation of blood in their neighbourhood. The article concludes by evaluating the consolidation, effectiveness and degree of satisfaction of the project, and suggesting that this model can be used to form the basis of ideas for educational proposals of other social institutions.

Key words: altruism; gift theory; service learning; blood donation; utilitarianism; interest; blood bank; education for citizenship.

\section{SOMMAIRE}

Le don de sang volontaire recommandée par l'Organisation Mondiale de la Santé et qui est effectué par des banques de sang, en plus de contribuer au système de santé avec un élément thérapeutique essentiel, est un dispositif qui régénère l'interaction sociale et de l'éducation à la citoyenneté. Dans ce cadre, l'article commence en affirmant pourquoi la donation altruiste est mieux que la comercialization et pourquoi la théorie du don - ce que la sociologie a développé à partir de l'œuvre de Marcel Mauss - justifie ainsi la possibilité de répondre à la demande de sang de cette façon. A partir de ces considérations, il est indiqué que les banques de sang sont des institutions sociales qui effectuent trois fonctions de base: technique, civique et pédagogique. L'article poursuit en développant la proposition éducative de Banc 
de Sang i Teixits de Catalunya. Un programme basé sur la méthode d'apprentissage par le service qui invite les jeunes à se former et d'élaborer une proposition de communication pour promouvoir le don de sang volontaire dans leur environnement. Le document conclut en évaluant la consolidation, l'efficacité et la satisfaction du projet, et en suggérant que ce modèle peut être utilisé pour élaborer des propositions éducatives des autres institutions sociales.

Mots clés: l'altruisme; la théorie du don; apprentissage par le service; don de sang; l'utilitarisme; l'intérêt; la banque de sang; l'éducation à la citoyenneté.

\section{INTRODUCCIÓN}

Sabemos desde hace tiempo que hay procesos educativos completamente entrelazados con otros procesos sociales. Conocemos hechos e instituciones sociales que no son educativas, pero que realizan importantes acciones formativas (Tri1la, 1986). Eso es justamente lo que ocurre con la donación de sangre y con la tarea que llevan a cabo los bancos de sangre. En la actualidad, la donación de sangre, además de proveer de productos sanguíneos a los hospitales, puede ejercer una función cívica y educativa de alto relieve. Esa es la tesis que deseamos justificar y ejemplificar en este escrito.

La sangre no se puede fabricar y a la vez resulta imprescindible en múltiples actos médicos. No podemos fabricarla, pero en cambio contamos con la tecnología y el conocimiento para obtenerla, tratarla, guardarla y transfundirla. Si es tan necesaria y no se puede producir, pero se puede manipular sin peligro para la salud, nos queda la posibilidad de obtenerla a partir de la que produce el cuerpo humano. Y aquí surge la cuestión central: ¿cómo obtener una pequeña parte de la sangre que poseen los seres humanos? Se han empleado dos procedimientos: conseguirla a través de la donación altruista o comprarla pagando un precio por ella. Optar por cualquiera de los dos caminos tiene hondas consecuencias sociales y expresa una manera distinta de entender la sociedad.

En este marco situamos las reflexiones que se desarrollan en este escrito y en particular lo hacemos a partir de una viva recomendación de la Organización Mundial de la Salud: promover universalmente la donación altruista de sangre como el mejor método para satisfacer la demanda que generan los sistemas sanitarios (OMS, 2011). Es precisamente a partir de este punto donde empiezan a plantearse los objetivos de este escrito: 1) sintetizar los argumentos que muestran que es mejor la donación altruista de sangre que su compraventa, 2) explicar en qué teoría de la acción humana se apoya la convicción de que es posible satisfacer de manera altruista las demandas de sangre en una sociedad dominada por el interés; 3) mostrar por qué los bancos de sangre se han convertido en agentes sociales con una triple función: técnica, cívica y educativa; 4) presentar la metodología pedagógica del aprendizaje servicio como una de las vías más adecuadas para realizar la función educativa que en la actualidad pueden desarrollar los bancos de sangre; 
5) explicar el proyecto de promoción de la donación de sangre basado en el aprendizaje servicio que ha puesto a punto el Banc de Sang i Teixits de Catalunya (BST); y 6) evaluar dicho proyecto educativo y comprobar que contribuye a promocionar la donación altruista de sangre.

\section{NO TODO TIENE PRECIO}

Nos interesa empezar este escrito con el debate sobre los límites de lo que se puede comprar con dinero. Queremos iniciar nuestra reflexión en este punto porque la controversia sobre lo que se puede y lo que no se puede adquirir en el mercado aborda, como uno de sus casos particulares, la posibilidad y la conveniencia de conseguir mediante su compra la sangre que se usará en la actividad médica. Por supuesto se trata de un debate que afecta a otros aspectos de la realidad humana y que resulta especialmente relevante en una época en que las leyes del mercado invaden sin ninguna prudencia todos los rincones de la sociedad.

Partimos de una pregunta inicial: ¿existen cosas que el dinero no puede o no debe comprar? (Sandel, 2013). Naturalmente, hay cosas que no se pueden comprar con dinero. La amistad o un premio no se consiguen pagando una cantidad. Si alguien lo intenta de inmediato se destruyen las cualidades del supuesto producto y desaparece la amistad verdadera o el reconocimiento sincero. Hay cosas que no se pueden comprar. Otras en cambio se pueden comprar, pero probablemente no es correcto hacerlo. Pongamos otro ejemplo aducido por Sandel (2013): la compra de un riñón para practicar un transplante no afecta a ninguna de sus funciones biológicas. Sin embargo, hay buenas razones para no aceptar el comercio con este tipo de bienes. En primer lugar, por motivos de justicia: siempre acaban por vender los pobres y comprar los ricos. Está claro cuál sería la dirección del flujo de bienes y cómo se rompería la igualdad. En segundo lugar, su compraventa degrada y cosifica la humanidad de ambos actores, y de una manera especialmente dañina la del vendedor. Por tanto, aunque ciertos bienes pueden someterse a las leyes del mercado sin que pierdan sus cualidades, no conviene permitirlo.

Además, introducir la lógica comercial en ciertas actividades conlleva dificultades inesperadas. Cuando se introduce una compensación económica para premiar o favorecer la realización de conductas que ya se llevaban a cabo por deber cívico, altruismo o búsqueda del bien común, los resultados en lugar de mejorar empeoran. Los incentivos pensados para incrementar la aparición de conductas solidarias producen justamente lo contrario: perjudican el logro de unos buenos resultados. Cuando se substituye la motivación intrínseca por alguna compensación extrínseca, los incentivos -económicos o de otro tipo- acaban por corroer la voluntad cívica y dañar aquello que precisamente se quería potenciar. Mezclar la lógica comercial con el altruismo al final es moralmente destructivo y nada rentable (Hirsch, 1976).

Estas afirmaciones se han demostrado empíricamente en numerosas ocasiones. Frey (1997) comprobó como un grupo de estudiantes que participaban de forma altruista en una colecta económica obtenían mejores resultados que los 
conseguidos por otro grupo de estudiantes que participaban sabiendo que recibirían una compensación económica en función de los resultados obtenidos. También se comprobó que imponer pequeñas multas a los padres que llegan tarde a la guardería para recoger a sus hijos tan solo consiguió incrementar su tardanza. Cuando se comercializa algo que ya se sostenía o que podría sostenerse por medio de una motivación intrínseca, los resultados tienden a ser peores.

Estos argumentos y resultados los encontramos también y probablemente en su forma más paradigmática en el caso de la donación de sangre, tal como mostró Richard Titmuss (1970). A partir de la comparación entre el sistema de obtención utilizado en el Reino Unido, donde la sangre se consigue a partir de su donación, y el sistema de los Estados Unidos, donde convive donación y compra, Titmuss defendió la superioridad del sistema altruista por encima del que convierte la sangre en una mercancía sujeta a las leyes del mercado. Basa su postura en cinco líneas de razonamiento. En primer lugar, muestra hasta qué punto el sistema basado en el mercado es propenso a la escasez, al desperdicio y supone un coste económico cada vez más elevado. En segundo lugar, advierte que la sangre obtenida por el sistema de compra podría tener un mayor riesgo de contaminación, algo que no tiene por qué ocurrir en la actualidad, pero que tampoco se puede descartar totalmente que pudiera producirse. En tercer lugar, nos encontramos nuevamente con los argumentos de justicia y deshumanización: cuando la sangre entra en el mercado son los pobres los que la venden y los ricos los que con mayor frecuencia la reciben y, por otra parte, unos y otros sufren un proceso de cosificación en la que sus cuerpos y sus actitudes se convierten en mercancías sujetas a precio. En cuarto lugar, tampoco es recomendable imponer la lógica del mercado por encima de las motivaciones altruistas porque con ello se socava el sentimiento de deber vinculado a la donación y se debilita el espíritu cívico que impulsa a colaborar en favor del bienestar colectivo. Cuando se pasa del altruismo a la venta descienden las donaciones voluntarias y se empobrece la vida moral y cívica de la sociedad. Es decir, se pierde un espacio de manifestación de la ciudadanía y de educación moral que tiene consecuencias negativas en el conjunto de la vida colectiva, no únicamente en el ámbito de la donación de sangre. Por último, en quinto lugar, su postura es contraria a la de Arrow cuando argumenta que los comportamientos éticos y altruistas son una mercancía escasa que debemos economizar para emplearla únicamente en situaciones y momentos en los que no hay más remedio (Arrow, 1972). En su opinión, no es necesario que la sangre se obtenga vía donación altruista cuando se puede obtener en el mercado. De este modo guardamos el altruismo para necesidades más extremas. Este argumento supone que poseemos una cantidad fija de virtud que vamos consumiendo hasta agotarla del todo. Una imagen equivocada de la virtud y del altruismo. La virtud no es comparable a un depósito que se vacía, sino que es mejor verla como la competencia de un deportista que con la práctica consigue mejores resultados. De acuerdo con estos argumentos, para Titmuss es correcto que la política de obtención de sangre se base en la promoción de la donación altruista y en la repetida demanda de colaboración 
a la ciudadanía. Convertir la donación en un hábito individual y colectivo no es dilapidar virtud, sino construir un carácter moral fuerte, que no solo proporcionará mejores resultados en las colectas de sangre, sino que también contagiará a otros ámbitos de la vida común y contribuirá a crear una sociedad más solidaria.

\section{DON E INTERÉS}

Hemos visto que para cubrir las necesidades de sangre no parece acertado confiar en la lógica del mercado. Por tanto, queda justificada la posición hoy dominante que proclama que para cubrir las necesidades de sangre del sistema sanitario conviene basarse en la donación voluntaria (OMS, 2011).

No obstante, la defensa de esta postura nos plantea nuevos interrogantes: ¿en una sociedad regida por el interés, es sensato esperar que las donaciones gratuitas logren cubrir las necesidades existentes? y ¿en qué teoría de la acción y la motivación humana basamos la confianza en las posibilidades y la superioridad del altruismo sobre el interés? Ciertamente, el clima intelectual dominante no permite suponer que tales expectativas vayan a cumplirse con facilidad, o simplemente que se consigan alcanzar alguna vez. La conducción de lo humano por medio de la razón económica, que de forma tan penetrante logró establecer el pensamiento utilitarista, ha invadido el espacio social y hace muy complejo imaginar la posibilidad de lograr por la vía altruista los objetivos de donación de sangre. Sin embargo, tanto los éxitos alcanzados hasta este momento por las políticas de donación gratuita de sangre, como algunas alternativas sociológicas basadas en el paradigma del don propuesto por Marcel Mauss (2009), dan a entender que es posible imaginar formas de intercambio no basadas en el contrato y el comercio. Veamos qué suponen a grandes rasgos el utilitarismo y la teoría del don.

En la actualidad, el utilitarismo y quizás una de sus últimas derivaciones, el neoliberalismo, copan el imaginario teórico de una parte importante del pensamiento económico y de las ciencias sociales. Parten de una primera afirmación básica: los seres humanos persiguen por encima de todo su propio interés, de manera que su búsqueda se convierte en el único motor de la vida humana. Además, para alcanzar mayores cotas de felicidad aplican una racionalidad calculadora que busca maximizar los beneficios. Tales principios configuran una visión egoísta de los individuos y de la sociedad que, sin embargo, se justifica al asegurar que si todo el mundo busca aumentar el propio beneficio se producirá la mayor cantidad posible de bienestar para el mayor número de personas. En este paradigma, la donación altruista de sangre tiene un anclaje débil, lo natural sería poner precio a la donación en tanto que medio para incentivarla y permitir también el logro de beneficio a las personas que proporcionan este bien.

Tal como ya hemos afirmado, pese a reconocer la importancia del interés y el cálculo, no podemos explicar todos los hechos de la realidad-como, por ejemplo, el éxito creciente de las campañas de donación de sangre- sin recurrir a un principio explicativo ajeno al mercado. Esto es precisamente lo que nos propuso 
Mauss con el paradigma del don y que parte de la sociología y la antropología actual (Caillé, 1989, 1994, 2000, 2009; Godbout, 1992, 2000) se han encargado de recordar y desarrollar. No es cierto que el don sea una práctica social del pasado, en la actualidad la obligación de dar, recibir y devolver es un principio social todavía vigente.

Retomando las aportaciones de Mauss, podemos afirmar que la obligación de dar, recibir y devolver que detecta en las sociedades primitivas constituye el dinamismo fundamental que produce el vínculo social y que lo hace por encima de las fuerzas del intercambio y el interés. Este descubrimiento se opone frontalmente a los postulados centrales del pensamiento utilitarista. El interés no siempre fue el criterio organizador y motor de lo social. Quizás antes que él o en tensión con él, el don constituyó un dinamismo universal en las sociedades primitivas. Pero no solo en las sociedades primitivas, hoy podemos encontrar la lógica del don en múltiples ámbitos de lo social. Desde lo que nos ocupa en este escrito, la donación altruista de sangre a desconocidos, hasta la obligación de dar que permanece como norma fundamental en las relaciones sociales primarias, en las relaciones cara a cara de amistad, familia o vecindad. La obligación de dar es básica en todas aquellas relaciones en las que la persona es más importante que su función social. No obstante, también la encontramos en las relaciones sociales secundarias, donde lo impersonal, el mercado o el cálculo son más relevantes que las personas singulares. Allí la obligación de dar, recibir y devolver coexiste con el interés y el mercado, y contribuye a crear una red de confianza que, entre otras funciones, es precisamente lo que hace posible el éxito del intercambio mercantil. Por tanto, la lógica del don también está presente en las sociedades actuales en una relación de colaboración y competición con la lógica del interés.

Si las lógicas del interés personal y del don pueden convivir en una relación de cooperación y competición de modo que ninguna de ellas ocupe el espacio de la otra, hemos establecido las condiciones que nos permiten afirmar que es posible confiar en que la donación altruista de sangre puede ser un mecanismo suficiente para satisfacer por completo las necesidades médicas. Nada nos impide afirmar que un buen trabajo de promoción de la donación puede lograr motivar el lado altruista de la ciudadanía y conseguir el nivel de donaciones requerido, y quizás otros resultados menos aparentes.

\section{DON DE SANGRE}

Hasta ahora hemos presentado dos ideas: 1) que hay bienes a los que no conviene poner precio, como la sangre, y 2) que la coexistencia de utilitarismo y teoría del don explica la posibilidad de producir bienes tanto dentro como fuera del mercado, justificando así el éxito de las campañas de donación altruista de sangre en una sociedad en la que domina el principio del interés. A partir de aquí, debemos mostrar hasta qué punto la donación de sangre sigue la lógica de la teoría del don y qué consecuencias se siguen para los bancos de sangre. 
La teoría del don formulada por Marcel Mauss (2009) afirma que las sociedades primitivas no se fundamentan en prácticas utilitaristas como el mercado, la compraventa o el contrato, sino sobre la triple obligación de dar, recibir y devolver. Se rivaliza en generosidad para ser reconocido como plenamente humano y, al cumplir con la obligación de dar, recibir y devolver, se establecen sólidos lazos de relación personal. Gracias a este proceso de reconocimiento y creación de vínculos que desarrolla el don se diluye la violencia, se produce confianza y se da forma a la comunidad.

¿Tiene algo que ver la donación de sangre con los dinamismos de la teoría del don? ¿La donación de sangre puede contribuir a crear comunidad y desarrollar sentimiento de ciudadanía? Si anticipamos lo que diremos a continuación, se puede afirmar que la donación de sangre en parte cumple con los principios de la teoría del don y en parte se distancia de ellos al introducir importantes modificaciones. Veamos los cambios más relevantes.

A diferencia del don tradicional, la donación de sangre se fundamenta en el anonimato -nunca sabemos quién será el receptor-y, en consecuencia, el don de sangre se aleja de la relación interpersonal característica tanto del don tradicional como del don en el ámbito de las relaciones sociales primarias. El don se ofrece a un desconocido.

Por otra parte, la donación de sangre, aunque quizás pueda generar sentimiento de obligación moral en los donantes, se caracteriza por la libertad, gratuidad y espontaneidad del donante. Se motiva a los posibles donantes, pero nunca se les exige que donen, ni pierden derechos si no donan. De acuerdo con estas características de la donación de sangre, tampoco es obligatoria la reciprocidad del receptor.

Finalmente, la donación de sangre es imposible sin la mediación de los bancos de sangre, entidades que se convierten en participantes esenciales del proceso de dar, recibir y devolver. De principio a fin, los bancos cumplen diferentes papeles que convierten las acciones de dar, recibir y devolver en algo más complejo y menos inmediato que el don tradicional. En consecuencia, los bancos de sangre tienen hoy una responsabilidad fundamental para conseguir que la donación siga expresando los valores del don tradicional, aunque las formas de presentarse se hayan modificado sustancialmente.

¿Cómo se manifiesta el proceso de dar, recibir y devolver en el caso de la donación de sangre y cuál es el papel de los bancos de sangre? El proceso comienza con una tarea que en buena parte está encomendada a los bancos de sangre: despertar el deseo de ayudar dando sangre. La donación de sangre es una posibilidad técnica y una necesidad terapéutica que se debe explicar y mostrar repetidamente porque no es evidente. La conveniencia de dar sangre debe hacerse visible porque no surge de manera natural e inmediata en el curso de las relaciones personales o sociales. Se requiere, por el contrario, que una entidad médica explique la necesidad de la donación de sangre para así despertar la voluntad de ayuda altruista. Para lograr estos objetivos, los bancos se esfuerzan en mostrar la necesidad de los componentes 
sanguíneos para llevar a cabo determinados actos médicos, se esfuerzan en alertar de la frecuente falta de reservas para cubrir adecuadamente la demanda y, finalmente, se esfuerzan en conseguir que los posibles donantes se sientan personalmente concernidos por tales necesidades y se ofrezcan para paliarlas. Se trata, en definitiva, de un proceso de motivación de los potenciales donantes para despertar en ellos la voluntad de ayudar. Para concluir esta primera etapa, los bancos acogen y tratan a todas aquellas personas que desean dar sangre. La donación de sangre no es un proceso ni transparente ni inmediato, sino que está impulsado por un agente mediador, los bancos de sangre.

El siguiente momento del proceso de donación de sangre se centra en el mismo acto de decidir donarla y hacerlo, algo que cada sujeto realiza movido por el deseo de ayudar a un desconocido. La voluntad de ayuda aparece cuando el potencial donante imagina al otro, lo imagina como alguien necesitado y percibe finalmente la posibilidad de ayudarlo. El don de sangre supone un dinamismo de empatía anónima: el otro es un sujeto real pero desconocido. En cambio quien recibe directamente la ayuda es el banco de sangre. Por este motivo decimos que el banco es el receptor del don de sangre, aunque sea en calidad de intermediario que lo vehiculará hasta el enfermo. Pero si es receptor, aunque sea receptor-mediador, debe estar dispuesto a agradecer al donante y, explicita o implícitamente, a declarar que velarán para devolverle la ayuda si un día la precisa. Estamos ante el primer bucle del don de sangre.

El segundo bucle se inicia cuando cualquier unidad hospitalaria, tras pedir el producto sanguíneo al banco, se convierte en donante ficticio, en realidad de nuevo actúa de intermediario entre el donante y el receptor. El altruismo del donante queda oscurecido por el deber profesional de atención de la institución sanitaria. Por su parte, el receptor también tiene más dificultades para reconocer y agradecer la virtud del donante y la donación adquiere el carácter de acto normal en un correcto sistema de salud. Por consiguiente, hace falta un mayor esfuerzo de los profesionales de la medicina para mostrar el espíritu del don y de los receptores para reconocerlo. Por último, el receptor también está llamado a devolver el don, aunque lo hará de forma mucho menos inmediata y directa que en el caso del don tradicional. Ante todo puede hacerlo agradeciendo los servicios sanitarios recibidos y, en caso de ser médicamente posible, aumentando su disposición a dar sangre o a participar en otras actividades en favor de la comunidad. Con ello se cierra el segundo bucle del don de sangre.

Hemos mostrado hasta qué punto la donación de sangre participa de la lógica del don y la modifica. En relación a lo que nos preocupa en este artículo hemos encontrado una novedad especialmente relevante: el papel mediador de los bancos de sangre. Los bancos motivan la donación, reciben el don de sangre, llevan a cabo una primera devolución, a continuación son ellos (o las instancias hospitalarias) quienes donan a los receptores necesitados, reciben su agradecimiento y, finalmente, quizás hacen visible a los receptores y al conjunto de la sociedad todo lo implícito e invisible que hay en el don de sangre. Estos dos bucles de donación 
otorgan a los bancos de sangre un rol que va mucho más lejos que el de una instancia técnico-médica.

\section{Función Cívica y EDUCATIVA De los bancos De SANGRE}

En las páginas anteriores hemos supuesto repetidamente que la lógica del don expresada en el triple movimiento de dar, recibir y devolver es un dinamismo constitutivo de la individualidad y de la sociedad. Lo es porque la práctica del don crea alianzas entre actores, desarrolla el sentido de pertenencia a la colectividad y construye el espacio de lo común. Y participar en un proceso de esta naturaleza contribuye al reconocimiento y a la formación de la identidad individual y, por otra parte, favorece la constitución de una sociedad con sentido. En síntesis, la práctica del don educa, forma ciudadanos y crea condiciones de convivencialidad.

Si la práctica del don contribuye a alcanzar esos objetivos y los bancos de sangre son mediadores imprescindibles del don de sangre, se sigue que la tarea que realizan los bancos va a tener una influencia difícil de negar en la educación personal, en la formación de ciudadanos y en el camino hacia una sociedad más convivencial. Por lo tanto, como ocurre tantas veces las instituciones sociales cumplen simultáneamente dos funciones: llevan a cabo aquella que les es propia -en el caso de los bancos realizar colectas, tratar la sangre y fraccionarla, y suministrar los componentes sanguíneos a los hospitales-, pero a la vez llevan a cabo una tarea social y formativa al encarnar la lógica del don.

Por el simple hecho de existir y operar, los bancos de sangre ya ejercen una cierta función social y educativa. A estos procesos formativos podemos llamarlos educación informal (Trilla, 1986). Sin embargo, tales procesos informales pueden hacerse explícitos y amplificarse mediante programas sistemáticos de comunicación y acciones educativas planificadas. En este caso, los procesos informales se han transformado en conscientes e intencionales. En la actualidad, los bancos de sangre suelen llevar a cabo ambos tipos de proceso.

En relación a los procesos educativos intencionales, los bancos de sangre realizan frecuentes campañas de comunicación para recordar a los donantes habituales la importancia de que vuelvan a dar, para conseguir nuevos donantes y para fidelizar a unos y otros. Por otra parte, algunos bancos de sangre desarrollan programas educativos en centros escolares para difundir su tarea, educar en valores y animar a que en el futuro los jóvenes se conviertan en donantes habituales. Son propuestas educativas basadas en la difusión de un mensaje y quizás en la realización de algún taller práctico para tratar alguno de los aspectos presentados (Bosch, Climent y Puig, 2009). Hasta aquí el camino que suelen recorrer los bancos de sangre y otras entidades sociales. 


\section{EDUCAR ES PEDIR AYUDA}

El cambio que introdujo en esta dinámica educativa el Banc de Sang $i$ Texits de Catalunya (BST) fue sencillo y profundo, pensó que no solo debía ofrecer conocimientos a los jóvenes, sino que por encima de todo les debía pedir ayuda para promocionar la donación de sangre entre la ciudadanía.

No se puede dar sangre hasta los dieciocho años, de manera que al alumnado de Primaria y Secundaria no se les puede pedir que sean donantes, pero en cambio se les puede proponer que colaboren en la difusión de la misión del banco, que contribuyan a difundir la necesidad de donar sangre en el barrio en el que viven y entre sus familiares y vecinos, y que lo hagan por todos los medios comunicativos que se les ocurra. Tal como hemos dicho, el cambio es simple: se pide ayuda a los jóvenes para hacer más efectivas las campañas habituales de donación de sangre que desarrolla el BST.

En cierto modo podemos decir que el BST utiliza la lógica del don, que ya aplica en el ámbito de la promoción de la donación altruista de sangre entre la ciudadanía, a su función educativa. Se pide a los jóvenes que apliquen su tiempo, su creatividad y su esfuerzo a producir un bien - una campaña de comunicación- y que la pongan al servicio de los objetivos del banco de sangre. Es decir, que donen gratuita y solidariamente un bien que han producido con su esfuerzo. Un bien que el BST recibe, disfruta y devuelve, al menos en forma de reconocimiento. De este modo, se introduce a los jóvenes en la lógica del don.

Pedir ayuda -introducir en la lógica del don-conlleva hondas consecuencias educativas. Quien pasa de receptor de bienes a poder ofrecerlos se convierte en alguien que participa, que contribuye al bien común, que se convierte en ciudadano, que al verse capaz gana poder personal, que incrementa su autoestima con el reconocimiento, que adquiere múltiples competencias relacionadas con la tarea que realiza y, por encima de todo, aprende por experiencia que el interés personal no es el único motor de la vida, que el dinamismo del dar, recibir y devolver funciona en muchos ámbitos de la vida social y puede contrabalancear el peso excesivo del mercado. No olvidamos, por otra parte, que los jóvenes aprenden también conocimientos científicos relacionados con el mundo de la sangre y la transfusión, aprenden destrezas comunicativas y, como ya hemos advertido, reflexionan sobre valores.

El cambio que ha introducido el BST en sus proyectos educativos va en la línea de la mejor, aunque escasamente realizada, pedagogía renovadora del siglo pasado (Trilla, 2009). Aquella que con diferentes formulaciones afirma que aprender supone realizar algo en favor de la comunidad. Una afirmación que encontramos en Dewey con su actividad asociada con proyección social (Dewey, 1926), en Makarenko con el trabajo socialmente necesario (Makarenko, 2006) o en Baden Powell con los proyectos de servicio a la comunidad (Baden Powell, 2008; Martín, 2012). 


\section{El APRENDIZAJE SERVICIO COMO PEDAGOGÍA DEL DON}

La concreción metodológica de la pedagogía del don, con sus dos caras: pedir ayuda y realizar algo a favor de la comunidad, se ha desarrollado de forma amplia y completa gracias al aprendizaje servicio, una metodología que como veremos hizo suya y adaptó a su realidad el banco de sangre y tejidos.

¿Qué es el aprendizaje servicio? Aunque no tenemos una aproximación única al concepto y encontramos distintos matices en función de la perspectiva desde la que se trabaja, en el momento de definir lo esencial del aprendizaje servicio hay unanimidad en considerarlo como una actividad compleja de enseñanza y aprendizaje que integra el servicio a la comunidad con el estudio académico (Kaye, 2004; Furco y Billing, 2002; Tapia, 2001; Puig, 2009). En el aprendizaje servicio se unen dos elementos conocidos para crear una propuesta pedagógica nueva. Aprendizaje y servicio quedan vinculados en una relación circular en la que ambas partes salen beneficiadas: el aprendizaje adquiere sentido cívico y el servicio se convierte en un taller de conocimientos y valores.

Aunque no resulta sencillo fijar el origen del aprendizaje servicio, es obligado citar al menos la aportación de John Dewey (1926). En concreto, nos referimos al principio de la "actividad asociada con proyección social", que junto con otros principios como por ejemplo los de actividad, interés o experiencia completan su pensamiento pedagógico. Con la expresión uactividad asociada con proyección social" se quiere destacar, en primer lugar, la necesidad que la educación parta de la experiencia real de sus protagonistas, pero de una experiencia realizada cooperativamente con iguales y con adultos -el desarrollo siempre es social- y, finalmente, que dicha actividad no se cierre sobre sí misma, sino que redunde en beneficio de la comunidad. Es decir, que se haga en provecho del entorno social que acoge a los jóvenes, ya que sólo implicándose en el perfeccionamiento del orden social se logrará la plena integración en la sociedad de cada nueva generación de jóvenes.

En relación a su arquitectura pedagógica, el aprendizaje servicio combina tres tareas básicas: responder a una necesidad social, ofrecer un servicio a la comunidad y adquirir conocimientos, competencias y valores (Kendall, 1990; Eyler y Giles, 1999). El aprendizaje servicio es una metodología pedagógica que abre la escuela a necesidades sociales de la comunidad en la que está ubicada. Se quiere romper con el aislamiento que a veces sufren los centros educativos y con la lejanía de la realidad que suelen arrastrar los programas. Se pretende que la educación se abra a la vida y sea sensible a los problemas, dificultades o deficiencias que presenta su entorno más próximo. Sin embargo, el aprendizaje servicio no se limita a la detección de necesidades, sino que por encima de todo pretende implicar a los jóvenes en la realización de un servicio a la comunidad. Por servicio entendemos una acción real, que va más allá de las palabras o las intenciones, y que se centra en la realización de una contribución a la comunidad, alejándose todo lo posible del asistencialismo y buscando que entre quien da y quien recibe la ayuda se cree 
un lazo de afecto y de reciprocidad. Por último, el aprendizaje servicio no solo es detección de necesidades y realización de un servicio a la comunidad, sino que a todo ello se le añade una fuerte preocupación por vincular ambos elementos al aprendizaje escolar. Es un método pedagógico que pretende que el alumnado adquiera contenidos conceptuales, procedimentales y de valor, pero además logra transmitir competencias para la vida en la medida que invita a los alumnos a enfrentarse a problemas reales. Las maneras de llevar a cabo la conexión entre servicio y aprendizaje pueden ser variadas. Se deben encontrar formas de relación que permitan aplicar el conocimiento al servicio y, por otra parte, conseguir que el servicio sea una experiencia que permita impulsar la adquisición de nuevos saberes.

\section{El PROYECTO DE APRENDIZAJE SERVICIO DEL BST}

El Banc de Sang i Teixits (BST) diseñó un proyecto de aprendizaje servicio para pedir a los jóvenes que se implicaran en una acción de promoción de la donación de sangre en su entorno próximo. Partieron de los dinamismos básicos del aprendizaje servicio y los aplicaron a sus características y posibilidades, así como a sus finalidades y tareas habituales. Este proceso se desarrolló a través de un plan piloto que partió del esbozo de un protocolo pedagógico de actuación -el diseño de una práctica de aprendizaje servicio para implicar a jóvenes en la promoción de la donación de sangre-, protocolo que luego se probó repetidamente, se evaluó y se modificó en los aspectos que podían mejorarse (Graell, 2010). El resultado de este proceso, el protocolo de actuación, consta de cuatro etapas: 1) Presentar el proyecto a la institución educativa; 2) Adaptar el proyecto a las necesidades del centro; 3) Desarrollar el proyecto con los jóvenes, y 4) Agradecer a los participantes, evaluar el proyecto y prever su continuidad.

Presentar el proyecto a la institución educativa. El primer paso es entrar en contacto con el centro, informar del proyecto, pedir su colaboración y empezar a crear lazos de complicidad con la dirección. Se trata también de adecuar el proyecto a la realidad particular de cada centro educativo. Las principales acciones que se llevan a cabo para lograr este propósito son:

- Informar del proyecto a la dirección del centro.

- Acordar las bases del trabajo conjunto.

- Fijar una persona de referencia en cada entidad.

- Solicitar el consentimiento de los padres.

Adaptar el proyecto a las necesidades del centro. Una vez que el centro ha aceptado realizar el proyecto, se hace indispensable desarrollar la adaptación del proyecto a sus particularidades. Por este motivo, los proyectos de aprendizaje servicio que se quieran replicar en múltiples centros educativos han de ser flexibles para facilitar la acomodación a la realidad y circunstancias de cada centro. Esta etapa requiere llevar a cabo acciones como: 
- Concretar el proyecto: destinatarios, formación y calendario de las acciones.

- Informar de los detalles de la realización del proyecto al claustro y a los padres.

- Establecer un documento guía que recoja los acuerdos alcanzados y los temporalice.

Desarrollar el proyecto con los jóvenes. Cuando la planificación ha llegado a su fin, es el momento de aplicar el proyecto, un proceso que consta de tres momentos: formar al alumnado, preparar la campaña de promoción y llevarla a cabo durante los días precedentes y también durante el día de la donación. Esta tercera etapa se concreta en los siguientes pasos:

- Preparar la formación: seleccionar los contenidos científicos, comunicativos o de valores, así como los materiales más adecuados.

- Presentar el proyecto a los participantes para que lo asuman como propio.

- Desarrollar las actividades de formación.

- Idear, preparar y realizar la campaña comunicativa.

- Buscar espacios de reflexión con los jóvenes.

Agradecer a los participantes, evaluar el proyecto y prever su continuidad. Como en cualquier experiencia educativa basada en la lógica del don, al finalizar el proceso se deben buscar fórmulas y momentos para agradecer el esfuerzo realizado por los distintos participantes. También conviene hacer balance, evaluar el programa y ver qué se puede mejorar. De este modo, se podrá valorar si la experiencia ha sido positiva y si se puede volver a realizar. Las principales actividades de cierre son las siguientes:

- Agradecer a los jóvenes participantes su labor, así como a los centros educativos y otras personas implicadas.

- Realizar una evaluación del proceso desde la perspectiva de todos los implicados.

- Analizar las posibilidades de replicar el proyecto y, en caso afirmativo, llevar a cabo una primera planificación.

El diseño del proyecto fue impulsado por el Banc de Sang i Teixits y el Grup de Recerca en Educació Moral (GREM) de la Universidad de Barcelona y se desarrolló durante un periodo de cuatro años durante los cuales de manera piloto se trabajó con distintos centros educativos y de ocio (Graell, 2010). El proceso permitió probar, evaluar y mejorar el proyecto al menos durante cuatro círculos de acción y reflexión que condujeron al protocolo pedagógico que hemos resumido. Además se pusieron a punto materiales de distinta índole para acompañar el proceso de aplicación, así como materiales pedagógicos para el alumnado. Una vez concluida la fase de pilotaje del proyecto, el BST lo incorporó plenamente a 
su plan de trabajo, formó un equipo para conducirlo y fue atrayendo al resto de personal del banco relacionado con el proceso de donación, principalmente el equipo de promotoras, el personal sanitario que atiende las unidades móviles y el resto de personal implicado. Todos ellos fueron informados y formados para contribuir al proyecto. Al finalizar el pilotaje y producirse la incorporación como línea de trabajo del banco, comienza un segundo periodo de evolución del proyecto: su normalización. En este momento lo importante ya no es diseñar el protocolo de actuación, sino evaluar los resultados de su aplicación generalizada. A ello dedicamos el siguiente apartado.

\section{EVAlUACIÓN DEL PROYECTO DE APRENDIZAJE SERVICIO DEL BST}

Después de seis cursos escolares durante los cuales el BST ha aplicado de manera ininterrumpida el proyecto, se cuenta ya con resultados suficientes para evaluar alguno de sus aspectos más relevantes. Nos parece que merece la pena detenernos en tres aspectos: la consolidación del proyecto, su efectividad en relación a la donación de sangre y, finalmente, el nivel de satisfacción e impacto que genera en los participantes. Los resultados nos indicarán el acierto del proyecto en tanto que práctica educativa impregnada por la lógica del don.

\subsection{Consolidación del proyecto}

Entendemos por consolidación del proyecto el proceso mediante el cual se le da firmeza y solidez. La consolidación supone un conjunto de medidas de orden diverso que han de permitir al proyecto del BST desarrollar su camino, no diluirse ni desaparecer y, al menos durante algunos años, crecer hasta llegar a un nivel acorde con las necesidades y las posibilidades disponibles. El mejor modo de constatar que el proyecto se ha consolidado es analizar la evolución de los centros participantes y de los jóvenes que han intervenido en él. Durante los seis cursos analizados, el proyecto se ha aplicado un total de 258 veces con la participación de 138 entidades, ya que algunas han repetido experiencia. De estas entidades, 95 son centros educativos y 43 instituciones de tiempo libre. Sin embargo, lo más elocuente es el crecimiento anual de experiencias y el crecimiento de los participantes, tal como nos indican los cuadros siguientes.

El número de experiencias y de participantes no ha cesado de crecer año tras año, lo cual indica que el programa ha tenido el apoyo de la dirección del BST, que ha logrado recursos para su funcionamiento -hecho que explica el salto que se produce entre el cuarto y el quinto año-y, por último, que su propuesta ha sido bien recibida por las instituciones educativas a las que se dirige. 
Figura 1. NÚMERO DE EXPERIENCIAS

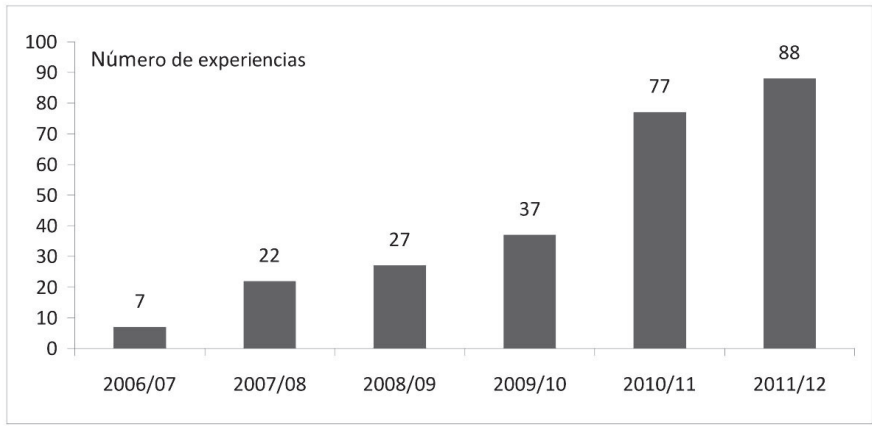

(FuENTE: Banc de Sang i Teixits de Catalunya)

Figura 2. NÚMERO DE PARTICIPANTES

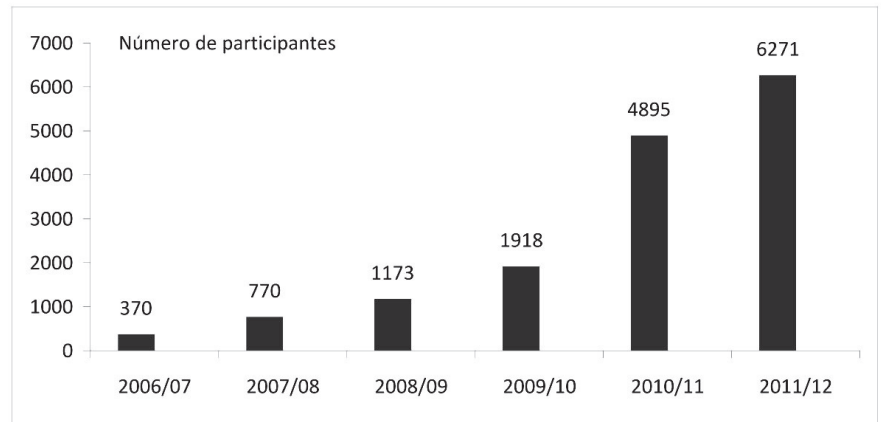

(Fuente: Banc de Sang i Teixits de Catalunya)

\subsection{Efectividad del proyecto}

Entendemos por efectividad del proyecto la capacidad de lograr aquello que se desea. En el caso que nos ocupa, conseguir que los jóvenes lleven a cabo una campaña comunicativa que logre atraer a los donantes habituales y a algunos nuevos. Como veremos, en ambos aspectos los resultados son positivos y demuestran que el proyecto es efectivo; es decir, que el trabajo gratuito ofrecido por los jóvenes produce unos resultados tangibles, positivos y que de ningún modo podrían haberse logrado sin su colaboración.

En primer lugar, cada vez que se desarrolla el proyecto, los alumnos idean, producen y aplican una campaña de comunicación para promover la donación de sangre entre sus vecinos. Estas campañas son variadas y emplean diferentes 
recursos, pero suelen coincidir en el reparto de hojas volantes, el pegado de carteles y el buzoneo de cartas. En estos tres aspectos el volumen de trabajo desarrollado por los jóvenes ha sido muy notable y, por encima de todo, merece la pena destacar que el BST de ninguna manera hubiese podido realizar un volumen de actividad parecido. Es decir, el servicio realizado por los jóvenes es una aportación relevante y útil, aunque no substituye la responsabilidad y las tareas habituales del BST. Además del número de hojas volantes repartidas, carteles colgados y cartas entregadas, los jóvenes han participado en infinidad de conversaciones cara a cara en las que han explicado la misión del BST y han invitado a sus interlocutores a dar sangre. Finalmente, a menudo han intervenido en programas de radios y de televisiones locales y han publicado escritos en la prensa. Como ya se ha dicho, un elevado nivel de servicio, del todo inaccesible si se hubiese de comprar a precios de mercado.

\subsection{ACCIONES DE PROMOCIÓN}

Figura 3. NÚMERO DE DONACIONES

\begin{tabular}{|c|c|c|c|}
\hline ACCIONES & REPARTIR VOLANTES & COLGAR CARTELES & REPARTIR CARTAS \\
\hline Número & 103.200 & 18.060 & 131.113 \\
\hline
\end{tabular}

(Fuente: Banc de Sang i Teixits de Catalunya).

En segundo lugar, el volumen total de donaciones logrado por las campañas ha sido importante. Pero quizás lo más relevante sea el número de primeros donantes y de ofertas que por algún motivo no se pueden efectuar. También merece la pena destacar que las campañas en las que han participado jóvenes pueden considerarse como muy buenas. En este sentido, el BST considera que una salida de cuatro horas al menos debe proporcionar 20 donaciones. Las campañas con participación de jóvenes han producido una media de 55 donaciones por salida. A continuación puede verse el número de donantes por cada curso escolar, así como su desglose en donantes, primeros donantes y ofrecimientos que no pudieron realizarse.

Merece la pena comentar que el descenso en las donaciones en el último curso, que coincide con un aumento de jóvenes participantes, puede deberse a las oscilaciones que provocan las grandes campañas. Muchos participantes en una campaña no significan necesariamente un mayor número de donaciones. Por otra parte, algunas campañas pueden estar sufriendo la pérdida del efecto novedad que siempre provocan las primeras realizaciones. 
Figura 4. ANÁLISIS DE LAS DONACIONES

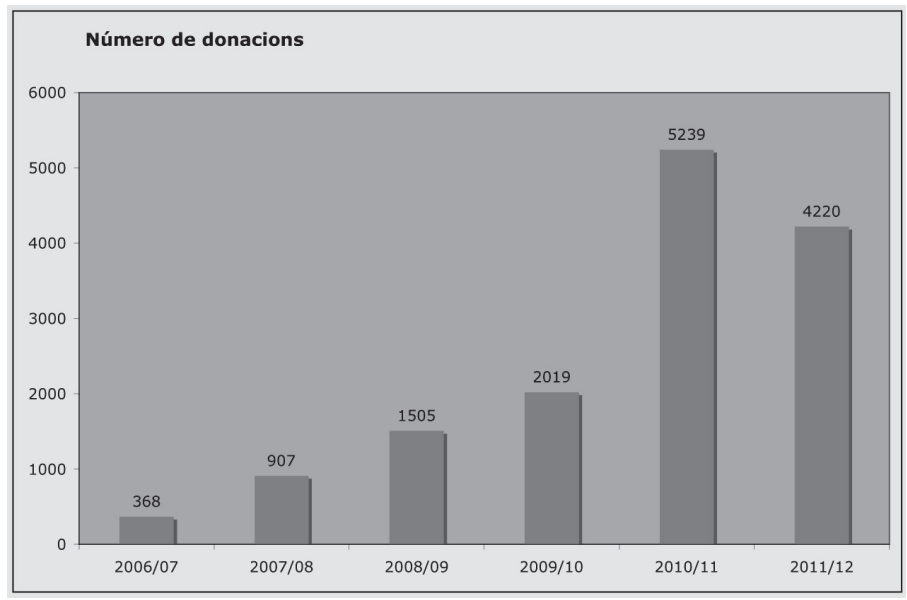

(Fuente: Banc de Sang i Teixits de Catalunya).

FiguRA 5. COMPARACIÓN DE CAMPAÑAS CON Y SIN APS

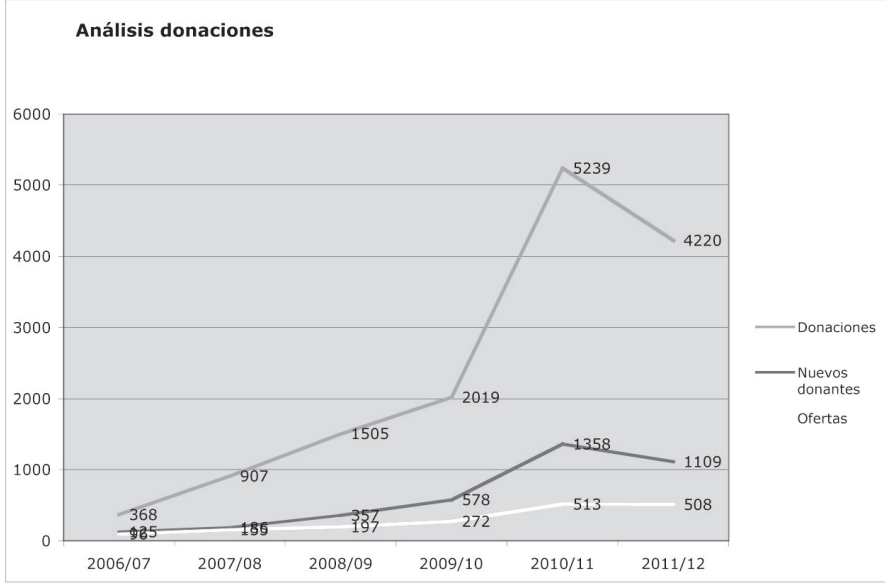

(Fuente: Banc de Sang i Teixits de Catalunya).

Para terminar el análisis de la efectividad del programa, quizás el dato más significativo sea la comparación entre los resultados obtenidos en una campaña sin participación de jóvenes y los obtenidos en una con participación. En condiciones similares veremos como las campañas en las que hay una implicación altruista 
de jóvenes producen mejores resultados. Aunque no es fácil encontrar campañas equivalentes, en los casos en que ha sido posible establecer la comparación los resultados son muy positivos y en todos los casos considerados se logra un mayor número de donaciones.

\begin{tabular}{|c|c|c|c|}
\hline CAMPAÑAS DEL BST & $\begin{array}{c}\text { DONACIONES } \\
\text { SIN APS }\end{array}$ & $\begin{array}{c}\text { DONACIONES } \\
\text { CON APS }\end{array}$ & $\begin{array}{c}\text { INCREMENTO } \\
\text { DONACIONES }\end{array}$ \\
\hline I & 95 & 115 & 20 \\
\hline II & 57 & 65 & 8 \\
\hline III & 15 & 45 & 30 \\
\hline IV & 23 & 33 & 10 \\
\hline V & 16 & 36 & 20 \\
\hline VI & 11 & 41 & 30 \\
\hline
\end{tabular}

(Fuente: Banc de Sang i Teixits de Catalunya).

\subsection{Satisfacción e impacto en los participantes}

De entre las diferentes aproximaciones a la satisfacción y al impacto de las actividades de promoción de la donación de sangre realizadas por escolares vamos a destacar tres: la valoración global que merece la actividad a los participantes, la convicción de haber alcanzado el objetivo propuesto y, por último, la intención de ser donante en el futuro ${ }^{2}$. Esta encuesta se ha pasado a 985 jóvenes pertenecientes a 23 centros educativos al finalizar la realización de la actividad organizada conjuntamente con el $\mathrm{BST}^{3}$.

La primera cuestión pedía a los alumnos participantes que valorasen la actividad en su conjunto del uno al diez. La nota media obtenida fue un 8,74 , donde ninguna valoración fue inferior a siete y hubo varias notas máximas. Por lo tanto, se trata de una muy alta valoración a partir de opiniones poco dispares.

1. Las campañas se han realizado en: I) Escola López Vicuña (Barcelona) (Campaña de doble duración); II) Casal de Joves (Sant Just Desvern); III) Escola Safa-Horta (Barcelona); IV) Hospital Joan XXIII (Tarragona) (20012-13); V) Hospital Joan XXIII (Tarragona) (2011-12); VI) Hospital Sant Joan (Reus).

2. La totalidad de los datos han sido obtenidos por el Banc de Sang i Teixits de Catalunya.

3. La evaluación de satisfacción se ha llevado a cabo en los siguientes centros: Escola Solc Nou, Col-legi Mare de Déu dels Àngels, Escola Vedruna, Escola Meritxell, Escola Jeroni de Moragas, Escola Torres Amat, Col-legi Maristes Champagnat, Escola Mestre Morera, Col-legi Mare de Déu de Lourdes, Col·legi L’Anunciata, Escola Betúlia, Escola El Cim, Escola Jaume Balmes, Escola La Farigola, Escola La Llàntia, Escola Rosselló Pórcel, Escola Sot del Camp, Escola Torre Llauder, INS Salvador Segui, Institut Escola Francesc Cambó, EJI Mollerussa, La Salle La Seu y Aspirantat Sant Josep. 
La segunda aproximación quería valorar hasta qué punto los participantes consideraban que habían alcanzado el objetivo de la actividad: concienciar a las personas de su entorno sobre la conveniencia de donar sangre. Cuando se les preguntaba sobre esta cuestión, el 82,98\% contestó que sí habían logrado transmitir a personas de su barrio la necesidad de dar sangre, mientras que el 17,02\% declaraban que no lo habían conseguido. En una alta medida los alumnos se sentían satisfechos del logro alcanzado.

Por último, cuando se les preguntaba si habían pensado en ser donantes de sangre en el futuro, el 61,7\% declaró que sí, el 13,3\% que no y el 25,0\% que no lo sabían. Aunque estas opiniones quedan muy alejadas del momento en que realmente se podrán plantear si quieren ser donantes o no, indican de forma muy clara que muchos jóvenes se han dado personalmente cuenta de la conveniencia de ser en el futuro donantes de sangre.

En definitiva, hemos visto que el programa del BST está consolidado, es efectivo y produce en sus participantes una notable satisfacción y un alto impacto. Estos motivos justifican la voluntad de mantenerlo como una parte de las campañas de promoción de la donación cada vez más incorporada en la cultura y la práctica del Banc de Sang i Teixits.

\section{CONClusiones}

A lo largo de estas páginas hemos intentado dar cuenta de los seis objetivos que nos planteábamos al principio. El primero, mostrar por qué es mejor la donación altruista de sangre que la compraventa, nos ha permitido ver que no es posible poner precio a todos los bienes sin peligro de desnaturalizarlos o echar a perder la motivación de las personas para contribuir al bien común. El segundo objetivo, explicar en qué teoría de la acción humana se basa la convicción de que es posible satisfacer las necesidades de sangre por la vía del altruismo, nos acercó a la teoría del don con su lógica basada en el dar, recibir y devolver. Una lógica que la donación de sangre encarna con suficiente claridad, aunque con algunas diferencias que hemos señalado. El tercer objetivo, explicar por qué los bancos de sangre cumplen una función técnica, cívica y educativa, nos permitió ver que el modo como un banco recolecta sangre expresa una forma de entender la sociedad, de construirla $y$, en definitiva, de formar a la ciudadanía. Hoy los bancos de sangre son instituciones que expresan y educan el altruismo, la convivencialidad y la búsqueda del bien común. El cuarto objetivo, presentar el aprendizaje servicio como la mejor metodología para realizar la función educativa que deben llevar a cabo los bancos de sangre, nos invitó a sintetizar los elementos claves del aprendizaje servicio y a mostrar que es una acertada manifestación pedagógica de la lógica del don. El quinto objetivo, lo cubrimos explicando la propuesta de aprendizaje servicio desarrollada por el BST para implicar a los jóvenes en la promoción de la donación de sangre. Finalmente, el sexto objetivo, se logró presentando una primera evaluación de la consolidación, efectividad y satisfacción del proyecto. 
A partir de estos resultados podemos concluir que los bancos de sangre que promueven la donación altruista expresan de un modo nuevo la lógica del don basada en el dar, recibir y devolver. Una lógica social que se diferencia de la tendencia utilitarista basada en la maximización del interés personal y que debería contribuir a contrarrestar la posición de dominio del mercado. Es por este motivo que podemos afirmar que los bancos de sangre son un buen ejemplo de una forma de proceder social basada en el altruismo, la ayuda mutua y la búsqueda del bien común que debería extenderse hacia otros ámbitos sociales. Por otra parte, para realizar su misión y en beneficio del conjunto de la sociedad, los bancos de sangre pueden aplicar la misma lógica del don a sus programas educativos y solicitar ayuda a los jóvenes para que destinen tiempo e inteligencia a promover la donación de sangre. Finalmente, la propuesta implementada por el BST, que se basa en la metodología del aprendizaje servicio, expresa un línea formativa que progresivamente están adoptando más instituciones sociales para desarrollar programas educativos basados en el altruismo, la ayuda mutua, la construcción de lo común y la creación de una idea de la ciudadanía basada en la participación.

\section{REFERENCIAS BIBLIOGRÁFICAS}

Arrow, K. J. (1972) Gifts and Exchanges. Philosophy and Public Affairs, 1 (4), 343-362.

BADEN POWELl, R. (2008) Escoltisme per a nois. Vic, Eumo.

Bosch, C.; Climent, T. y Puig, J. (2009) Partenariado y redes para el aprendizaje servicio, en Puig, J. (comp.) Aprendizaje Servicio. Educación y compromiso cívico. Barcelona, Graó, pp. 127-149.

CAIllé, A. (1989) Critique de la raison utilitarire. Paris, La Découverte.

CAillé, A. (1994) Don, intérêt et désintéressement. Bourdieu, Gauss, Platon et quelques autres. Paris, La Découverte/Mauss.

Caillé, A. (2000) Anthropologie du don. Le tires paradigma. Paris, Desclée de Brouwer.

CAIllé, A. (2009) Théorie anti-utilitariste de l'action. Fragments d'une socilogie générale. Paris, La Découverte. (Cast.: Teoría anti-utilitarista de la acción. Fragmentos de una sociología general. Buenos Aires, Waldhuter, 2010).

Dewey, J. (1926) Los principios morales que cimentan la educación, en DeWEY, J. Ensayos de Educación. Madrid, La Lectura, 1-61.

Dewey, J. (1926) Ensayos de Educación. (Obras de Dewey, vol. II). Madrid, La Lectura.

Dewey, J. (1989) Cómo pensamos. Barcelona, Paidós.

Eyler, J. y GILES, D. E. (1999) Where's the Learning in Service-Learning? San Francisco: Jossey-Bass.

FreY, B. S. (1997) Not Just for the Money: An Economic Theory of Personal Motivation. Cheltenham (UK), Edgard Elgar Publishing.

Furco, A. y Billing, S. H. (2002) Service-Learning. The essence of the Pedagogy. Greenwich, Information Age Publishing.

Godbout, J. T. (1992) L'Esprit du don. Paris, La Découverte.

Godbout, J. T. (2000) Le don, la dette et l'identité. Homo donator vs homo oeconomicus. Paris, La Découverte and Syros.

GODELIER, M. (1996) L'Enigme du don. Paris, Fayard. 
Graell, M. (2010) Donació de sang i educació per a la ciutadania: una experiència d'aprenentatge servei. Barcelona, Universitat de Barcelona, tesis de doctorado.

Henrion, A. (2003) L'énigme du don de sang, approche ethnographique d'un don entre inconnus. Mémoire de fin d'étude. Université de Liège, Faculté de Philosophi et Lettres.

Hirsch, F. (1976) The Social limits to Growth. Cambridge (MA), Harvard University Press. http://dx.doi.org/10.4159/harvard.9780674497900

KAYE, C. B. (2004) The complete guide to service learning. Minneapolis, Free Spirit, 6-15.

Kendall, J. C. y otros (1990) Combining Service and Learning. A Resource Book for Community and Public Service (vol. I). Raleigh (North Carolina), National Society for Internships and Experiential Education.

Makarenko, A. (2006) Poema pedagògic. Vic, Eumo.

MarTín, X. (coord.) (2012) Per a una pedagogia del servei. Treball per proyectes projectes $i$ $A p S$. Valldoreix, Minyons Escoltes Guies Sant Jordi de Catalunya.

Martínez, M. (2008) Aprenentatge servei i responsabilitat social de les universitats. Barcelona, Octaedro.

Mauss, M. (2009) Ensayo sobre el don. Forma y función del intercambio en las sociedades arcaicas. Buenos Aires, Katz (original 1924).

Organisation Mondiale de la SANTÉ (2011) Dons de sang volontaires: objectif 100\%. Cadre mundial de l'action. Genève, Editions de l'oms.

PUIG, J. (coord.) (2009) Aprendizaje servicio. Educación y compromiso cívico. Barcelona, Graó.

Puig J.; Batlle, R.; Bosch, C. y Palos, J. (2006) Aprendizaje servicio. Educar para la ciudadanía. Barcelona, Octaedro.

Ruffie, J. y SOURNIA, J.-Ch. (1996) La transfusion sanguine. Paris, Fayard.

SANDEL, M. J. (2013) Lo que el dinero no puede comprar. Barcelona, Debate.

TAPIA, N. (2001) La solidaridad como pedagogía. El aprendizaje-servicio en la escuela. Buenos Aires, Ciudad Nueva.

TrTmuss, R. M. (1970) The gift relationship. From human blood to social policy. New York, The New Press.

TRILLA, J. (1986) La educación informal. Barcelona, PPU.

TRILLA, J. (2009) El aprendizaje servicio en la pedagogía contemporánea, en PUiG, J. (coord.) Aprendizaje Servicio. Educación y compromiso cívico. Barcelona, Graó, 33-52. 